\title{
Novel anesthetic agent remimazolam as an alternative for the asleep-awake-asleep technique of awake craniotomy
}

\author{
Takehito Sato ${ }^{*}$, Yumi Kato, Mayumi Yamamoto and Kimitoshi Nishiwaki
}

To the Editor,

Remimazolam is a novel ultrashort-acting benzodiazepine with the advantage of a faster onset and recovery than pre-existing benzodiazepines, such as midazolam [1]. Awake craniotomy (AC) is performed in patients with brain tumors that present in regions linked to language processing, with the aim of minimizing damage to language functioning [2]. There have been reports on administering dexmedetomidine [2], propofol $[3,4]$, and remifentanil, for the induction of anesthesia in AC; however, there are no reports on administering remimazolam. We describe anesthesia using remimazolam in the asleep-awake-asleep technique of $\mathrm{AC}$.

A 37-year-old man (height $175 \mathrm{~cm}$, weight $58 \mathrm{~kg}$ ) with a diagnosis of a brain tumor in the right cerebrum, without other medical histories, was scheduled for AC. Anesthesia management comprised a combination of general anesthesia and scalp blocks [4]. General anesthesia was induced with remimazolam (12 $\left.\mathrm{mg} \mathrm{kg}{ }^{-1} \mathrm{~h}^{-1}\right)$, remifentanil $\left(0.1 \mu \mathrm{g} \mathrm{kg}{ }^{-1} \mathrm{~min}^{-1}\right)$, and fentanyl $(75 \mu \mathrm{g})$. The patient lost consciousness $93 \mathrm{~s}$ after starting remimazolam infusion, with a cumulative dose of $20.3 \mathrm{mg}$. Bispectral Index (BIS) values were approximately 60 . Rocuronium $(20 \mathrm{mg}$ ) was administered, and $\mathrm{I}_{\text {-gel }}{ }^{\circ}$ size 5 was inserted. Anesthesia was maintained with remimazolam $\left(1 \mathrm{mg} \mathrm{kg} \mathrm{kg}^{-1} \mathrm{~h}^{-1}\right)$ and remifentanil $\left(0.12-0.15 \mu \mathrm{g} \mathrm{kg}{ }^{-1} \mathrm{~min}^{-1}\right)$, and the BIS value remained approximately 50 to 60 .

Administration of remimazolam and remifentanil was discontinued at the request of the neurosurgeon to awaken the patient. After $26 \mathrm{~min}$, the patient was fully awake, and the I-gel ${ }^{\circ}$ was removed. He awoke

\footnotetext{
* Correspondence: takesato@med.nagoya-u.ac.jp; takeoffflutter@yahoo.co.jp Department of Anesthesiology, Nagoya University hospital, 65 Tsurumai-cho, Showa-ku, Nagoya city, Aichi 466-8550, Japan
}

clearly and was cooperative; therefore, language mapping was performed safely. There was no incidence of adverse events such as restlessness, seizure, and pain during the awakening period. Approximately $100 \mathrm{~min}$ after arousal, the awake phase was completed; anesthesia was reinduced with remimazolam (12 mg $\mathrm{kg}^{-1} \mathrm{~h}^{-1}$ ) and remifentanil (0.1-0.12 $\left.\mu \mathrm{g} \mathrm{kg}^{-1} \mathrm{~min}^{-1}\right)$.

The operation was successfully completed, and the Igel $^{\circ}$ was removed $26 \mathrm{~min}$ after discontinuation of remimazolam. He experienced no delay in arousal or respiratory depression. The total dose of remimazolam was 327 $\mathrm{mg}$. The operating time was $300 \mathrm{~min}$, and the anesthesia time was $463 \mathrm{~min}$.

To date, propofol has primarily been used for anesthesia management of the asleep-awake-asleep technique of AC. However, the use of propofol has disadvantages, such as a risk of developing propofol infusion syndrome [5], vascular pain when infusing, and the absence of antagonist agents. Dexmedetomidine, a highly selective $\alpha 2$ agonist, has been widely used due to its sedative and analgesic effect and ability to preserve spontaneous breathing [2]. However, disadvantages of dexmedetomidine include delayed arousal, cardiovascular effects such as bradycardia and hypotension, and, as with propofol, the absence of an antagonist [4].

In this case, the patient fully awoke and was able to perform intraoperative language tasks during the AC. We suggest remimazolam to be an alternative option for general anesthesia for $\mathrm{AC}$; it is an ultrashortacting agent, and if delayed arousal occurred, flumazenil can be administered as an antagonist $[1,6]$.

Remimazolam could be safely and successfully used for anesthetic management of the asleep-awake-asleep technique of AC.

\section{Springer Open}

(c) The Author(s). 2020 Open Access This article is licensed under a Creative Commons Attribution 4.0 International License which permits use, sharing, adaptation, distribution and reproduction in any medium or format, as long as you give appropriate credit to the original author(s) and the source, provide a link to the Creative Commons licence, and indicate if changes were made. The images or other third party material in this article are included in the article's Creative Commons licence, unless indicated otherwise in a credit line to the material. If material is not included in the article's Creative Commons licence and your intended use is not permitted by statutory regulation or exceeds the permitted use, you will need to obtain permission directly from the copyright holder. To view a copy of this licence, visit http://creativecommons.org/licenses/by/4.0/. 


\section{Acknowledgements}

The authors would like to thank Editage (https://www.editage.jp) for the English language review.

\section{Authors' contributions}

YK and TS have carried out the management of anesthesia in this patient MY collected the patient data. TS wrote the manuscript. KN has reviewed and edited the manuscript. All authors read and approved the final version of the manuscript.

\section{Funding}

Not applicable

\section{Availability of data and materials}

Not applicable

\section{Ethics approval and consent to participate}

Written informed consent was obtained from the patient for publication.

\section{Consent for publication}

The patient provided written permission for the authors to publish the report.

\section{Competing interests}

All authors did not receive financial aid for this work and declare no conflicts of interest.

Received: 26 October 2020 Revised: 5 November 2020

Accepted: 10 November 2020 Published online: 17 November 2020

\section{References}

1. Wesolowski AM, Zaccagnino MP, Malapero RJ, Kaye AD, Urman RD. Remimazolam: pharmacologic considerations and clinical role in anesthesiology. Pharmacotherapy. 2016;36:1021-7.

2. Goettel N, Bharadwaj S, Venkatraghavan L, Mehta J, Bernstein M, Manninen $\mathrm{PH}$. Dexmedetomidine vs propofol-remifentanil conscious sedation for awake craniotomy: a prospective randomized controlled trial. $\mathrm{Br} J$ Anaesth 2016;116:811-21.

3. Sato T, Okumura T, Nishiwaki K. Preanesthesia scalp blocks reduce intraoperative pain and hypertension in the asleep-awake-asleep method of awake craniotomy: a retrospective study. J Clin Anesth. 2020;66:109946.

4. Prontera A, Baroni S, Marudi A, et al. Awake craniotomy anesthetic management using dexmedetomidine, propofol, and remifentanil. Drug Des Devel Ther. 2017:11:593-8.

5. Ichikawa T, Okuyama K, Kamata K, Masui K, Ozaki M. Suspected propofol infusion syndrome during normal targeted propofol concentration. J Anesth. 2020;34:619-23.

6. Doi M, Morita K, Takeda J, et al. Efficacy and safety of remimazolam versus propofol for general anesthesia: a multicenter, single-blind, randomized, parallel-group, phase IIb/III trial. J Anesth. 2020;34(4):543-53.

\section{Publisher's Note}

Springer Nature remains neutral with regard to jurisdictional claims in published maps and institutional affiliations.

\section{Submit your manuscript to a SpringerOpen ${ }^{\circ}$ journal and benefit from:}

- Convenient online submission

- Rigorous peer review

- Open access: articles freely available online

High visibility within the field

- Retaining the copyright to your article 